\title{
Changes in the Serum Lipids and Apolipoproteins in the First Four Weeks of Life
}

\author{
D. M. LANE AND W. J. MCCONATHY \\ Lipoprotein and Atherosclerosis Research Program, Oklahoma Medical Research Foundation, \\ Oklahoma City, Oklahoma 73104
}

\begin{abstract}
The neonatal serum lipid transport system was monitored in the $1 \mathrm{st}$ month of life to determine the impact of oral feeding (breast versus formula). Lipid and apolipoprotein levels were measured in the serum of normal newborn infants collected at birth, 3, 14, and 28 days of age. Fatty acid and neutral lipid studies were determined by gas-liquid chromatography and apolipoprotein levels were done by electroimmunoassay. Following collection of data, the results were divided into two groups corresponding to breast-fed (BF) or formula-fed (FF) infants. Only triacylglycerols at 3 days of age were significantly higher $(p<0.04)$ in FF infant serum when compared to BF levels. Unesterified cholesterol levels in both groups were similar at all intervals, the cholesterol esters were higher at 14 and 28 days in BF infants. ApoA-I and ApoB levels were higher at 3 days in FF, but ApoC-III levels were the same. At all other sampling times, no discernible differences in these parameters were found between BF and FF. For the infants as a group, changes in levels with increasing age were similar for both ApoA-I and cholesterol esters, as was the case for ApoB and triacylglycerols. However, numerous differences between $B F$ and FF were seen in molecular forms of triacylglycerols and cholesterol esters, reflecting the dietary fatty acid differences between breast milk and formula. Analyses of the fatty acid content of these two diets demonstrated that human breast milk contained twice as much palmitic and oleic acid but only onehalf the linoleic acid of formula. In summary, little difference in serum lipid classes and apolipoprotein levels were found between BF and FF during the first 4 wk of life. However, striking differences in the molecular forms of both triglycerides and cholesterol esters between the two groups reflected the differences in the fatty acid composition of human milk and formula. (Pediatr Res 20: 332337, 1986)
\end{abstract}

\section{Abbreviations}

TG, triacylglycerol

C, cholesterol

$\mathrm{CE}$, cholesterol ester

TC, total cholesterol

ApoA-I, apolipoprotein A-I, the principal protein moiety of high-density lipoproteins (HDL)

ApoB, apolipoprotein $B$, the principal protein moiety of low-density lipoproteins

ApoC-III, apolipoprotein C-III

BF, breast fed

Received September 16, 1985; accepted December 6, 1985.

Correspondence to W. J. McConathy, Ph.D., Lipoprotein and Atherosclerosis Research Program, Oklahoma Medical Rescarch Foundation, Oklahoma City, OK 73104.

This grant was supported by Grants HL-23181, BRSG-RR05538, and funds of the Oklahoma Medical Research Foundation.
FF, formula fed

LCAT, lecithin cholesterol acyltransferase

The human infant in utero is supplied with nutrients via the placenta, with the principal caloric source being carbohydrate (1). In this state, the serum lipids and apolipoproteins are at low levels when compared to levels seen in adults (2-4). Shortly after birth, the plasma lipid transport system changes rapidly as the neonate's caloric source converts from primarily carbohydrate to a mixed source including fat (5). As others have shown $(6,7)$, some of the earliest changes in plasma lipoproteins have no relation to the introduction of nutrient intake by mouth but are related to other changes associated with the transition to postpartum life. Otherwise, the beginning of oral fat consumption is associated with increased plasma lipids.

To extend previous studies on the developmental aspects of plasma lipid transport $(2,4,8-10)$, the authors undertook a study on changes in this transport system during early postpartum life. We evaluated changes in the serum lipids and apolipoproteins following feeding in the first $4 \mathrm{wk}$ of life. To assure that factors previously shown to affect those levels (11) played no role, only normal newborn infants defined by strict criteria were included in the study. In addition, since a new variable was being added, i.e. feeding, the authors elected to compare the effects of breast feeding and formula feeding on serum lipid and apolipoprotein levels. Our working hypothesis was that no significant changes would be produced by the two different diets. In the following report, data are presented for the entire patient population and then for two separate populations, those fed breast milk and those fed formula.

\section{MATERIALS AND METHODS}

Subject recruitment. Prior to their admission to the labor and delivery suite, mothers-to-be were recruited from the practice of members of the Department of Obstetrics at a local hospital only if they were to have their infant subsequently followed by a member of the Department of Pediatrics at the same hospital. Permission to participate in the study was obtained in the delivery suite. Following delivery, if the newborn infant met the requirements for admission to the study, informed consent was obtained from the mother. Criteria for admission included: 1) cephalic vaginal delivery, 2) a birth weight between 2500 and $4000 \mathrm{~g}, 3$ ) a gestation period of 39-41 wk and 4) no perinatal disorder. A total of 30 infants entered the study (20 BF, $10 \mathrm{FF})$ with $18(13$ $\mathrm{BF}, 5 \mathrm{FF}$ ) completing the study.

Mothers of the newborn infants were free to choose whatever type of feeding they preferred. Although $60 \%$ of mothers had been expected to breast feed, the percentage was slightly higher. Mothers choosing to feed their infants formula were provided with a commonly available formula at no cost during the period 
that the study was performed. Discontinuation of breast feeding and a switch to formula feeding excluded that infant from the study.

Sample collection. Maternal blood was collected before delivery as a venous sample in the labor and delivery suite. Cord blood was obtained from the placenta immediately following the infant's birth. All subsequent samples were obtained from the infants by heel stick using a standard collection system at 2-3, $12-14$, and 26-28 days following delivery. Collection times were carefully adhered to and improper collection resulted in exclusion of that sample from the study.

Laboratory methods. Neutral lipid analyses for TG, C, and CE were performed by gas-liquid chromatography as previously described (12). This separation of neutral lipids yields $C$ and three forms of $\mathrm{CE}$. The three forms of $\mathrm{CE}$ are differentiated by the acyl carbon length of the esterified fatty acid and are designated: C-16, C-18, C-20. TGs are also differentiated by their esterified total acyl carbon content (TG-50, TG-52, TG-54). The sum of the various molecular forms was used to compute $\mathrm{TC}$ and $\mathrm{TG}$ levels. Total fatty acids were determined after saponification of human milk and formula as previously reported for plasma lipids (12).

Electroimmunoassays were used to determine apolipoproteins A-I, B, and C-III as previously described (11). In a limited number of maternal and cord samples, more extensive apolipoprotein analyses were performed using electroimmunoassays available in this laboratory (11). Double diffusion analyses were performed on $1 \%$ Difco-Bacto agar as previously described (4). LCAT activity was determined by a modified Glomset-Wright assay (13). All activity levels were compared with the maternal levels.

Statistical analyses for significant differences between the two groups at each sampling interval were performed by the $t$ test.

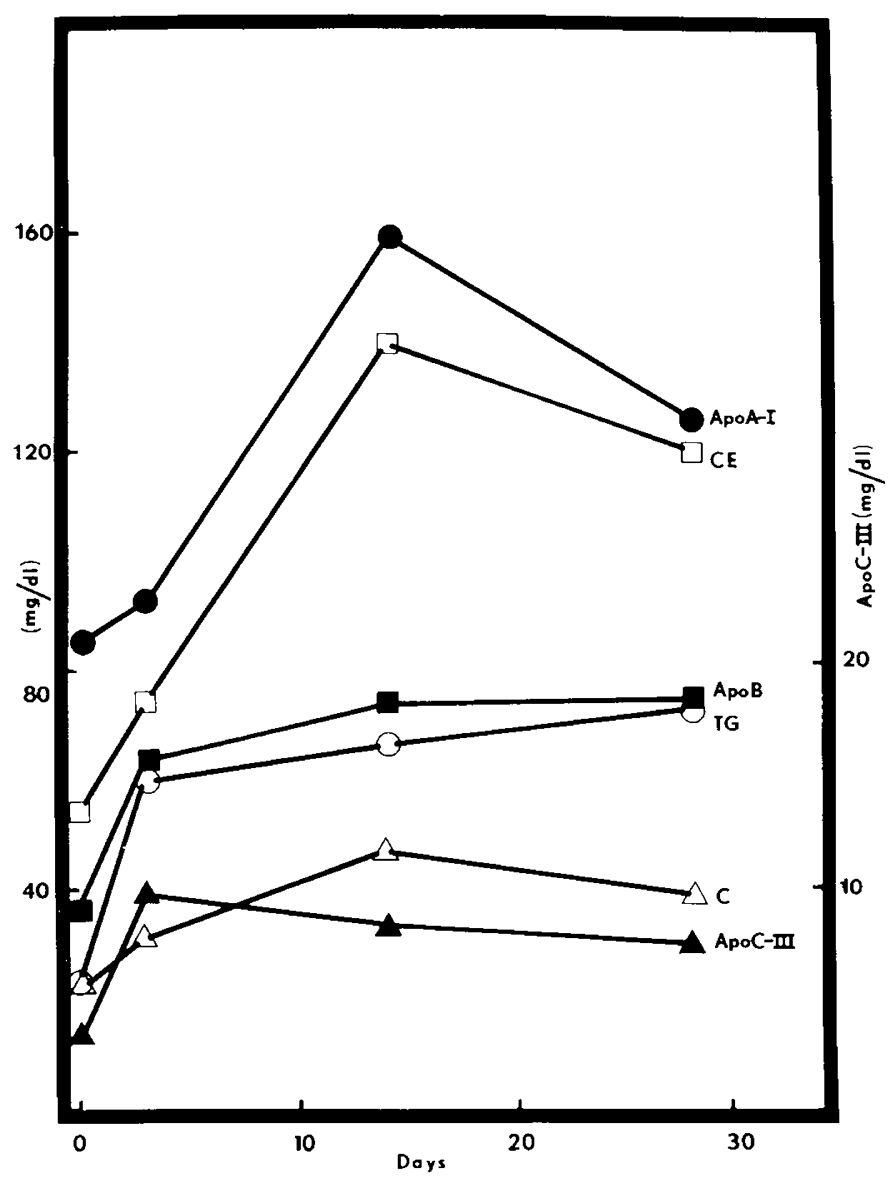

Fig. 1. Changes in lipids and apolipoproteins in the 1st month of life.
Table 1. Lipid and apolipoprotein correlational analyses during early neonatal life

\begin{tabular}{|c|c|c|c|c|}
\hline & & $n$ & $r^{*}$ & $p$ \\
\hline \multicolumn{5}{|c|}{ Total interval } \\
\hline \multicolumn{2}{|c|}{ ApoA-I vs ApoB } & 56 & 0.58 & 0.0001 \\
\hline & $\mathrm{C}$ & 53 & 0.31 & 0.023 \\
\hline \multirow[t]{5}{*}{ ApoB $v s$} & ApoA-I & 56 & 0.58 & 0.0001 \\
\hline & TG & 68 & 0.58 & 0.0001 \\
\hline & $\mathrm{TC}$ & 68 & 0.50 & 0.0001 \\
\hline & $\mathrm{C}$ & 68 & 0.48 & 0.0001 \\
\hline & $\mathrm{CE}$ & 68 & 0.48 & 0.0001 \\
\hline \multicolumn{5}{|c|}{ 3- to 14 -day interval } \\
\hline \multicolumn{2}{|c|}{ ApoA-I vs TG } & 19 & -0.41 & 0.078 \\
\hline & $\mathrm{TC}$ & 19 & 0.51 & 0.027 \\
\hline & $\mathrm{C}$ & 19 & 0.50 & 0.029 \\
\hline & $\mathrm{CE}$ & 19 & 0.46 & 0.049 \\
\hline \multirow[t]{4}{*}{ ApoB $v s$} & TG & 31 & 0.44 & 0.013 \\
\hline & $\mathrm{TC}$ & 31 & 0.52 & 0.0025 \\
\hline & $\mathrm{C}$ & 31 & 0.41 & 0.0227 \\
\hline & $\mathrm{CE}$ & 31 & 0.55 & 0.0012 \\
\hline
\end{tabular}

* Pearson correlation coefficients.

Table 2. Neonatal LCAT activity

\begin{tabular}{cccccc}
\hline & & Cord & \multicolumn{3}{c}{ Neonatal } \\
\cline { 4 - 6 } \cline { 4 - 6 } & Maternal & serum & 3-day & 14-day & 28 -day \\
\hline LCAT activity* & $130.8^{\dagger}$ & 34.5 & 42.1 & 65.9 & 56.2 \\
$(\mathrm{nmol} / \mathrm{ml})$ & $(51.2)$ & $(14.2)$ & $(19.4)$ & $(38.0)$ & $(32.2)$ \\
$n=$ & 5 & 9 & 12 & 8 & 8 \\
$\%$ Activity $\$$ & 100 & 26 & 32 & 50 & 43 \\
\hline
\end{tabular}

* Glomset-Wright assay.

$\dagger$ Mean (SD)

$\ddagger$ Values expressed as percentage of maternal level.

Pearson correlation coefficients were calculated using the Statistical Analysis System (SAS Institute, Inc, Carey, NC).

\section{RESULTS}

The lipid and apolipoprotein parameters for all infants from birth until 4 wk of age are presented in graphic form (Fig. 1). ApoA-I and CE had very similar patterns following birth and both reached a maximum at 14 days. Less pronounced but similar changes were noted for $\mathrm{C}$ while both $\mathrm{ApoB}$ and $\mathrm{TG}$ increased slightly after 3 days and ApoC-III decreased. Statistical correlations of these changes are presented both for all intervals (includes cord serum) and for the 3- to 14-day period (Table 1). For the entire study period, ApoA-I levels were significantly related to the levels of $A p o B$ and $C$. ApoB was related significantly not only to A-I but also to all of the lipid classes studied, i.e. TG, TC, C, and CEs. When the period from 3 to 14 days was evaluated, no significant relationship between ApoA-I and ApoB was found, suggesting that these apolipoproteins increase after feeding independently. In this time frame, ApoA-I was positively correlated with all $\mathrm{C}$ classes but was negatively correlated with $\mathrm{TG},(r=-0.41, p=0.078)$. ApoB remained significantly related to all lipid classes for this period.

Changes in neonatal LCAT activity were followed over the 1 st month of life. These are shown for the mother at delivery and the infant from birth through 28 days of age (Table 2). As expected, the LCAT levels of cord sera were substantially lower than those of maternal sera. Levels increased following birth in a pattern similar to ApoA-I and CE but were never greater than $50 \%$ of maternal levels.

Neutral lipid levels (Table 3) were compared for BF infants and FF infants over the same interval. Maternal values prior to 
delivery confirmed the known large concentration gradient of neutral lipids across the placenta between the maternal and fetal systemic circulations (1). Our hypothesis that no significant difference between BF and FF would be found in the neutral lipids levels following feeding was confirmed for all lipid classes except TGs. At 3 days of age, formula feeding produced a significantly higher TG level than the level in BF infants. This is consistent with the fact that mothers are not producing significant amounts of fat in the breast milk prior to this time. This differece was absent in the 14- and 28-day samples.

Table 3. Lipid levels of BF and FF infants

\begin{tabular}{|c|c|c|c|c|}
\hline & TG & $\mathrm{CE}$ & $\mathrm{C}$ & $\mathrm{TC}$ \\
\hline \multicolumn{5}{|l|}{ Mother } \\
\hline $\begin{array}{l}\text { Breast } \\
(n=20)\end{array}$ & $128.7(41.5)^{*}$ & $242.3(57.4)$ & $60.7(20.8)$ & $204.1(49.1)$ \\
\hline $\begin{array}{l}\text { Formula } \\
(n=7)\end{array}$ & $155.7(87.4)$ & $266.4(48.6)$ & $66.6(27.7)$ & $224.2(53.4)$ \\
\hline \multicolumn{5}{|l|}{ Cord blood } \\
\hline $\begin{array}{l}\text { Breast } \\
(n=20)\end{array}$ & $13.8 \quad(9.2)$ & $63.5(15.4)$ & $22.2(6.5)$ & $59.8(13.3)$ \\
\hline $\begin{array}{l}\text { Formula } \\
(n=7)\end{array}$ & $14.2(10.9)$ & $62.5(21.2)$ & $23.6 \quad(5.6)$ & $60.6(16.5)$ \\
\hline \multicolumn{5}{|l|}{ 3-Day } \\
\hline $\begin{array}{l}\text { Breast } \\
(n=20)\end{array}$ & $52.4(32.4) \dagger$ & $74.9(14.0)$ & $30.9 \quad(6.5)$ & $75.2(13.5)$ \\
\hline $\begin{array}{l}\text { Formula } \\
(n=9)\end{array}$ & $80.5(24.2)$ & $74.1(32.8)$ & $33.4 \quad(9.1)$ & $77.2(27.6)$ \\
\hline \multicolumn{5}{|l|}{ 14-Day } \\
\hline $\begin{array}{l}\text { Breast } \\
(n=16)\end{array}$ & $67.0(47.0)$ & $148.1(43.1)$ & $46.9(12.4)$ & $134.5(36.3)$ \\
\hline $\begin{array}{l}\text { Formula } \\
(n=6)\end{array}$ & $62.5(24.8)$ & $116.6(57.5)$ & $47.4(28.1)$ & $116.4(59.2)$ \\
\hline \multicolumn{5}{|l|}{ 28-Day } \\
\hline $\begin{array}{l}\text { Breast } \\
(n=13)\end{array}$ & $72.1(59.7)$ & $124.4(53.6)$ & $38.0 \quad(9.5)$ & $111.6(39.7)$ \\
\hline $\begin{array}{l}\text { Formula } \\
(n=5)\end{array}$ & $79.0(47.5)$ & $113.2(44.8)$ & $40.1(16.2)$ & $107.1(41.1)$ \\
\hline
\end{tabular}

* Mean (SD).

$\dagger$ Significant differences at $p<0.05$ level.
A more detailed analysis of the $\mathrm{C}$ and TGs species demon strated a qualitative difference between BF and FF infants' serum lipids (Fig. 2) while no such difference was seen in cord serum levels. Free $\mathrm{C}$ appears to be unaffected but the fatty acid ester of $\mathrm{C}$ were quite different. Quantities of C-18 CEs were similar ir both groups while the total amount of both C-16 and C-20 CE:

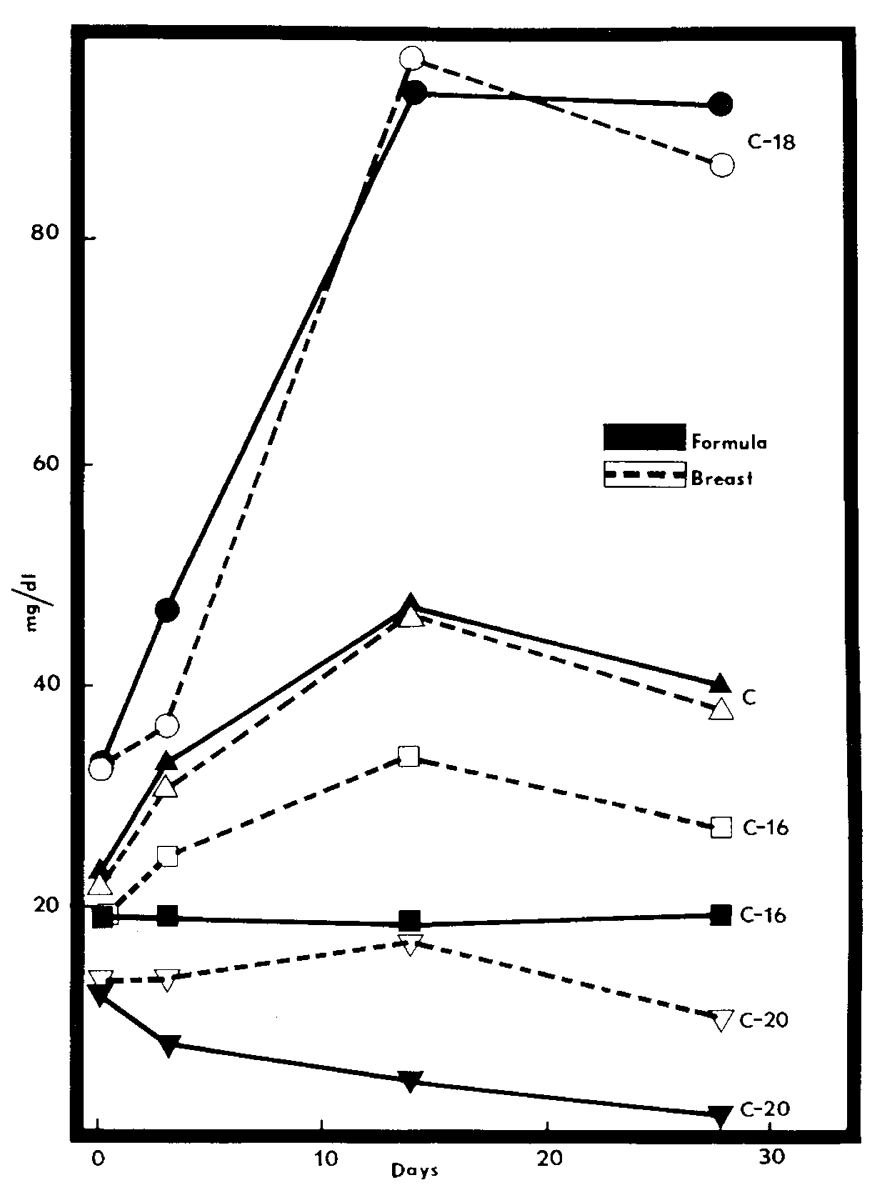

Fig. 2. Molecular species of $\mathrm{C}$ in serum of infants either $\mathrm{BF}$ or FF ir the 1st month of life. Arabic numeral refers to acyl carbon number of esterified fatty acid.

Table 4. Breast vs formula: wt composition of $C$ and $T G$ species during 1 st month of life

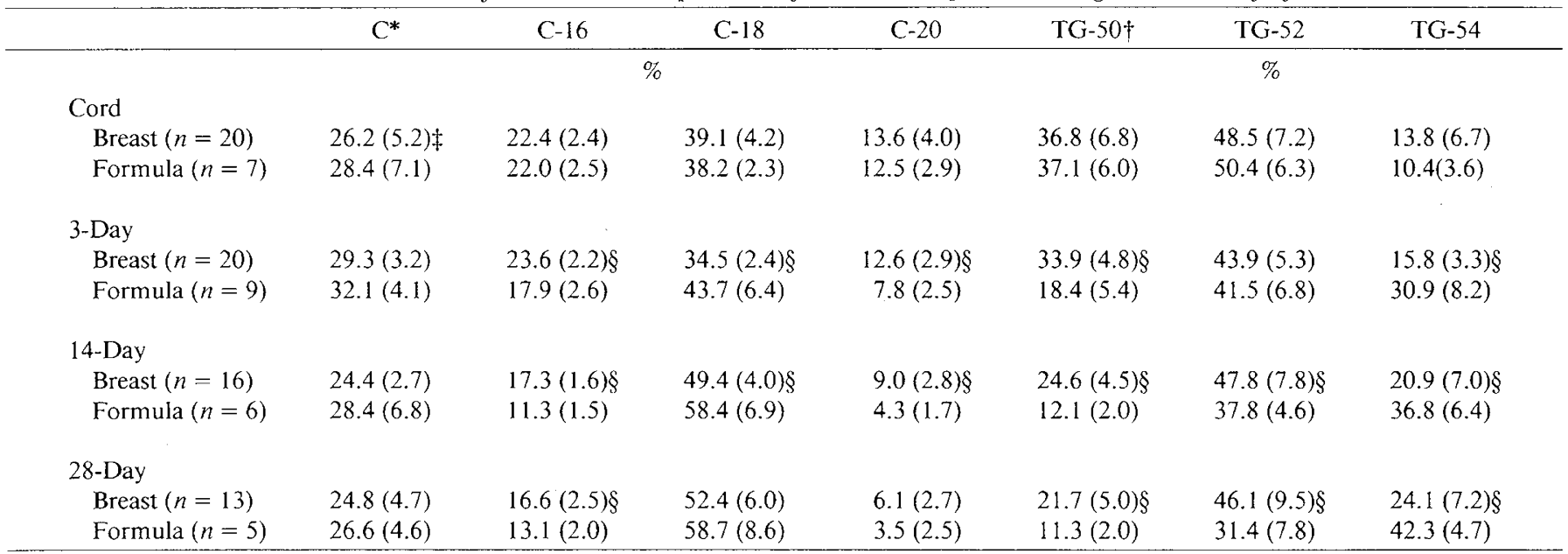

* Arabic numeral indicates acyl carbon length of esterified fatty acid.

$\uparrow$ Arabic numeral indicates acyl carbon number.

$\ddagger$ Mean (SD).

$\S p<0.05$. 


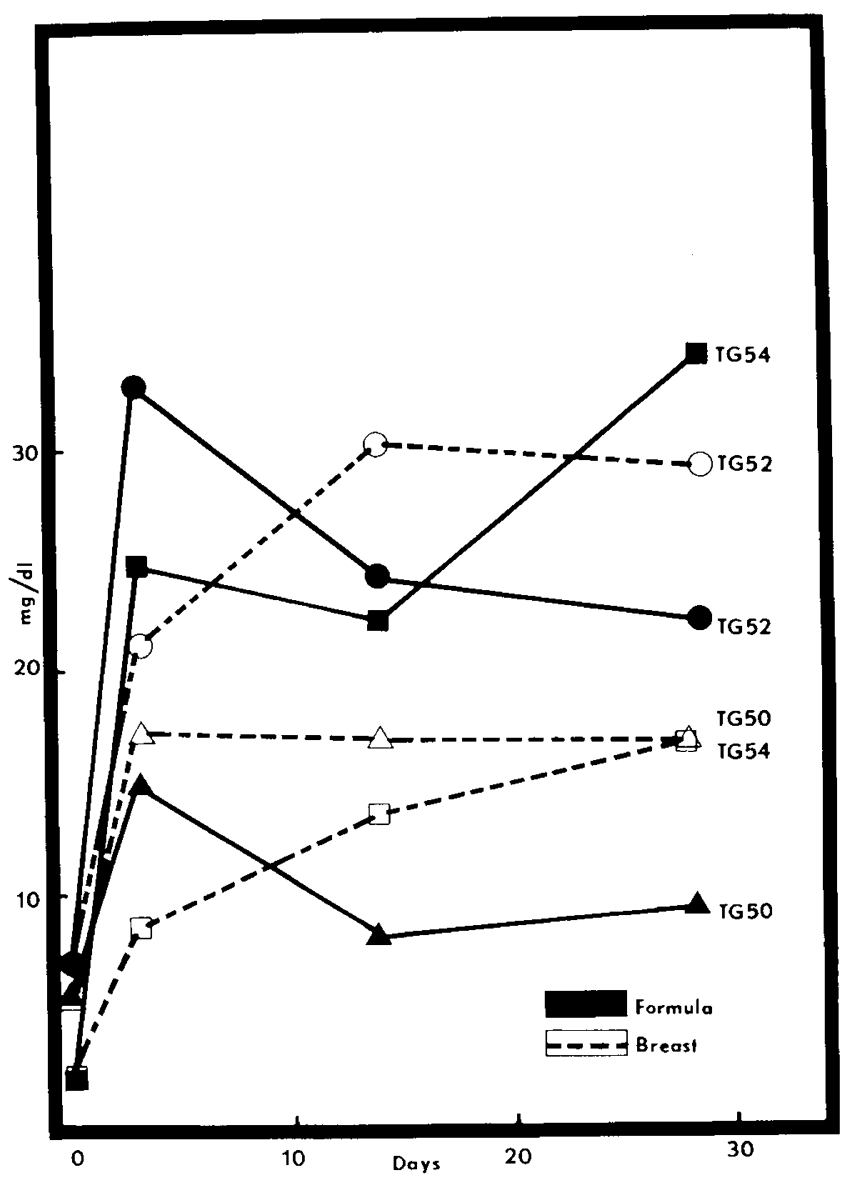

Fig. 3. Molecular species of TGs in serum of infants either BF or FF in the 1 st month of life. Arabic numeral represents acyl carbon number of esterified fatty acids.

in the $\mathrm{BF}$ infant were higher at each time point when compared to those seen in the FF infant. When expressed as percent of TC as shown in Table 4 , the differences were significantly different at every interval studied except for the C-18 and C-20 CEs at 28 days. TG species were also markedly affected by the type of feeding. In Figure 3, TG-50 and TG-52 rose early but fell to lower levels in FF infants throughout the sampling period while the TG-54 species became the predominant TG species at 28 days. Compositional differences (Table 4) were significant at all times except for TG-52 at 3 days of age.

The total fatty acid composition of human milk was compared with the formula used in this study (Table 5). The quantitative differences in fatty acid content between the two offer an explanation for these major differences in composition of $\mathrm{C}$ and triglyceride species. Large differences in fatty acids were found both on a weight basis and a percentage basis. Human milk contains twice as much palmitic and oleic fatty acids as formula but only one-half as much linoleic. The linoleic fatty acid in formula accounted for over $42 \%$ of its total fatty acid content, while it was only $16 \%$ of human milk. Analyses of other proprietary formulas demonstrated similar patterns of fatty acids in a number of formulas. A follow-up study was performed to determine whether breast milk might change its fatty acid composition over the time frame of this study. No changes were found in the fatty acid composition of breast milk of one individual followed for 73 days postpartum.

Apolipoproteins were examined for both qualitative and quantitative differences between BF and FF infants. The apolipoproteins A-I, A-II, B, C-II, C-III, D, and E were detected by double diffusion analyses in both mothers and infants at each sampling point. One apolipoprotein (ApoF) was not detected in cord serum as well as at 3 days of age but was present at 14 and 28 days of age. The absence or only trace levels of ApoF at 0 and 3 days was confirmed by electroimmunodiffusion. ApoF was found at 14 days and remained present at 28 days. No other major qualitative difference between $\mathrm{BF}$ and $\mathrm{FF}$ infants was noted.

Changes in apolipoprotein levels were observed for both $\mathrm{BF}$ and FF infants at the four sampling times (Table 6). ApoA-II increased rapidly following birth and began falling from its peak at 2 wk of age. The increase in ApoB was much less rapid though it peaked in FF infants at 3 days with leveling off by 14 days. No significant differences in apolipoprotein levels were found between the two groups. This may be a reflection of the limited number of infants, especially those fed formula, who were studied in the 4-wk period.

Weight changes from birth up to $26 \mathrm{wk}$ of age were monitored for both groups. Again, no significant difference in weight gain was found either during the study period or in the subsequent 26-wk follow-up after completion of study. The mean weight of both groups was similar at birth $(\mathrm{BF}, 3.38 \pm 0.37 \mathrm{~kg}$; FF, $3.54 \pm$

Table 5. Total fatty acid composition

\begin{tabular}{lcrrr}
\hline $\begin{array}{c}\text { Fatty acid } \\
\text { carbon no. }\end{array}$ & $\begin{array}{c}\text { Human milk } \\
(n=4)\end{array}$ & $\begin{array}{c}\text { Formula } \\
(n=3)\end{array}$ \\
\hline & g/liter & \multicolumn{1}{c}{$\%$} & \multicolumn{1}{c}{$g /$ liter } & $\%$ \\
14 & $11.7(5.11)^{*}$ & 6.3 & $6.8(1.7)$ & 4.8 \\
16 & $42.1(11.1)$ & 22.8 & $21.0(5.4)$ & 14.8 \\
$16: 1$ & $4.7(1.9)$ & 2.5 & $1.2(0.4)$ & 0.8 \\
18 & $16.9(3.3)$ & 9.2 & $8.8(2.1)$ & 6.2 \\
$18: 1$ & $75.4(18.8)$ & 40.9 & $35.5(8.5)$ & 25.0 \\
$18: 2$ & $29.9(8.0)$ & 16.2 & $60.7(15.3)$ & 42.7 \\
20 & $0.5(0.2)$ & 0.2 & $0.6(0.6)$ & 0.4 \\
$20: 1$ & $2.1(0.7)$ & 1.2 & $6.6(1.7)$ & 4.7 \\
$20: 4$ & $0.5(0.1)$ & 0.2 & $0.5(0.2)$ & 0.3 \\
$20: 5$ & $0.9(0.2)$ & 0.5 & $0.5(0.1)$ & 0.4 \\
& & & & \\
Total & 184.6 & & 142.1 & \\
\hline
\end{tabular}

* Mean (SD).

Table 6. Infant serum apolipoproteins

\begin{tabular}{|c|c|c|c|}
\hline & A-I & ApoB & C-III \\
\hline & & $\mathrm{g} / 100 \mathrm{ml}$ & \\
\hline \multicolumn{4}{|l|}{ Cord serum } \\
\hline $\begin{array}{l}\text { Breast } \\
(n=19)\end{array}$ & $87.1(19.5)^{*}$ & $37.3(21.8)$ & $5.0(1.4)$ \\
\hline $\begin{array}{l}\text { Formula } \\
(n=6)\end{array}$ & $77.2(44.1)$ & $32.5(11.9)$ & $5.0(1.7)$ \\
\hline \multicolumn{4}{|l|}{ 3-Day } \\
\hline Breast & $88.0(51.4)$ & $59.8(19.1)$ & $9.2(3.0)$ \\
\hline$n=$ & 11 & 15 & 12 \\
\hline Formula & $109.3(61.3)$ & $79.6(23.5)$ & $8.7(4.4)$ \\
\hline$n=$ & 3 & 4 & 6 \\
\hline \multicolumn{4}{|l|}{ 14-Day } \\
\hline Breast & $156.6(62.6)$ & $78.9(30.5)$ & $8.6(4.2)$ \\
\hline$n=$ & 6 & 9 & 13 \\
\hline Formula & $169.2(100.8)$ & $60.9(5.2)$ & $4.6(1.7)$ \\
\hline$n=$ & 2 & 3 & 2 \\
\hline \multicolumn{4}{|l|}{ 28-Day } \\
\hline Breast & $124.8(85.1)$ & $75.4(38.9)$ & $6.4(2.5)$ \\
\hline$n=$ & 5 & 9 & 8 \\
\hline Formula & $126.8(63.8)$ & $61.8(20.2)$ & $8.5(2.6)$ \\
\hline$n=$ & 5 & 3 & 4 \\
\hline
\end{tabular}

* Mean (SD) 
$0.32 \mathrm{~kg}$ ) and no significant association was found between type of feeding and subsequent weight gain.

\section{DISCUSSION}

Following delivery of normal infants who were either BF or FF subsequently, dramatic changes in both serum lipids and apolipoproteins were found during the first $4 \mathrm{wk}$ of life, consistent with previous reports $(2,14-17)$. In the present study, both apolipoproteins and major classes of lipids reached their maximum levels at 14 days, followed by a decline to lower levels at 28 days. Changes in lipids were similar for both $\mathrm{BF}$ and $\mathrm{FF}$ infants with some variation in levels of $\mathrm{TG}$ and total $\mathrm{C}$ at both 3 and 14 day sampling times but the levels reached at 28 days were similar for both types of feeding. The TC values at 28 days were in the lower 5 th percentile of the young adult population levels while $\mathrm{TG}$ levels were similar to the mean of this population [18).

The apolipoproteins had a pattern similar to the rise and fall of the lipids over the 1 st month of life. ApoA-I, the major apolipoprotein of HDL, peaked at 14 days for both types of feeding at a level higher than typical for a normolipidemic population of adults $(4,19)$, and at 28 days was at levels typical for the adult population. ApoB, the principal protein moiety of low-density lipoproteins, did not show as clear-cut a pattern but the BF infants had higher levels at 28 days than the FF infants. However, levels of $\mathrm{ApoB}$ at 28 days for both groups were in the lower range for normolipidemic adults (19). Accompanying the maximal levels of Apo-I and CE at 14 days was the maximum of LCAT activity consistent with the cofactor role of ApoA-I and CE being the product of LCAT action (20). These changes in the plasma lipid transport system appear to reflect the introduction of exogenous fat via the intestine. However, the initial sharp increase in lipids and apolipoproteins during the first $2 \mathrm{wk}$ of neonatal life may be due to a change in the equilibrium of the infant's system. The reason for the different pattern of appearance of ApoA-I and ApoB is unclear but may reflect the contrasting roles these apolipoproteins play in lipid transport in the vascular compartment. ApoB-containing lipoproteins deliver TG and $C$ to tissues primarily in an unidirectional mode $(21)$ to meet both energy and membrane formation requirements, while ApoA-I, in conjunction with LCAT, plays an important role in the redistribution of $\mathrm{C}$ between tissues (22).

Although not assessed quantitatively, the qualitative analysis of other apolipoproteins demonstrated the presence of all apolipoproteins previously reported to be present in cord serum (4) at each sampling time. The only exception to this was the absence of detectable ApoF by double-diffusion analyses in cord serum and at 3 days. The significance of this observation remains unclear but may be related to this acidic apolipoprotein's role in plasma CE metabolism (23).

The other aspect of early changes in the neonate's plasma lipid tiansport system was that associated with feeding two different types of dietary fat. The differences between the fatty acid composition of breast milk and the proprietary formula were striking. These differences were reflected in the molecular species of both plasma triglycerides and CEs. Formula when compared to breast milk had twice as much linoleic acid (18:2), the precursor of arachidonic acid and prostaglandins. Since the fatty acid composition of the body is a reflection of the dietary fatty acid composition $(24,25)$, this difference should be reflected in increased membrane fluidity and thus alterations in permeability (26) to various physiologic and nonphysiologic agents. In addition, the decrease in CEs having 20 carbons, presumably arachidonic acid in the FF infants, might be a reflection of the utilization of such esters in the formation of prostaglandins (27). However, the more plausible explanation for the reduction of arachidonic acid in CEs would be that the saturation of phospholipids with linoleic acid, the preferred substrate for LCAT
(22), limits the formation of cholesteryl arachidonate. Further evaluation of the mechanisms responsible for these changes and their potential effect on both development and long-term morbidity will require additional information and long-term prospective studies.

Birth and the introduction of dietary fat produce a striking change in the plasma lipoprotein system. Serum TG C, and CE levels increase rapidly, but the distribution of esters depends upon the type of fatty acid present in the diet. Apolipoproteins show similar changes, but the changes in Apo A-I and Apo-B from 3 to 14 days of age were not significantly correlated, suggesting that the initial production of ApoA-I and Apo-B following birth may be under separate control. The final result is a lipid transport system at 1 month of age closely resembling that of the young adult population but markedly different from the system present at birth.

Acknowledgments. The authors thank S. Slick, R.N. for assistance in recruitment of subjects and in obtaining informed consent, and O. Dick, L.P.N. for collection of samples following discharge from the Newborn Nursery. They also acknowledge the cooperation of both the Department of Obstetrics and the Department of Pediatrics at Presbyterian Hospital of Oklahoma City. We also thank D. Seikel and P. Kazori for technical assistance, and J. Pilcher for preparation of manuscript.

\section{REFERENCES}

1. Fredrickson DS, Breslow JL 1973 Primary hyperlipoproteinemia in infants Ann Rev Med 24:315-324

2. Rafstedt S 1955 Studies on serum lipids and lipoproteins in infancy and childhood. Acta Paediatr Scand [Suppl] 102:5-109

3. Tsang RC, Fallat RW, Glueck CJ 1974 Cholesterol at birth and age 1: comparison of normal and hypercholesterolemic neonates. Pediatrics $53: 458-470$

4. McConathy WJ, Lane DM 1980 Studies on the apolipoproteins and lipoproteins of cord serum. Pediatr Res 14:757-761

5. Melichar V, Novák M, Hahn P, Koldovsky O, Zeman L 1962 Changes in the blood levels of lipid metabolites and glucose following a fatty meal in infants. Acta Paediatr Scand 51:481-489

6. Zee P 1975 Lipid metabolism in the newborn. II. Neutral lipids. Pediatrics 41:640-645

7. Biezenski JJ 1975 Fetal lipid metabolism. Obstet Gynecol Ann 4:39-70

8. Lindquist B, Malmcrona, R 1960 Dietary fat in relation to serum lipids in the normal infant. Am J Dis Child 99:55-63.

9. Woodruff CW, Bailey MC, Davis JT, Rogers N, Coniglio JG 1964 Serum lipids in breast-fed infants and in infants fed evaporated milk. Am J Clin Nutr 14:83-90

10. Fomon SJ 1974 Fat. In: Fomon SJ (ed) Infant Nutrition. WB Sanders Co., Philadelphia, pp 152-181

11. Lane DM, McConathy WJ 1983 Factors affecting the lipid and apolipoprotein levels of cord sera. Pediatr Res 17:83-91

12. McConathy WJ, Blackett PR, Kling OR 1981 Studies on serum apolipoproteins and lipids in amniotic fluid and neonatal urine. Clin Chim Acta 111:153162

13. Glomset JA, Wright JL 1964 Some properties of a cholesterol esterifying enzyme in human plasma. Biochim Biophys Acta 89:266-276

14. Persson B, Gentz J 1966 The pattern of blood lipids, glycerol and ketone bodies during the neonatal period, infancy and childhood. Act Paediatr Scand 55:353-362

15. Friis-Hansen B, Clausen J 1971 Studies on serum lipoprotein in the neonatal period. Z Ernalhrung Swiss 10:253-263

16. Rosseneu M, Van Biervliet JP, Bury J, Vinaimont N 1983 Isolation and characterization of lipoprotein profiles in newborns by density gradient ultracentrifugation. Pediatr Res 17:788-794

17. Strobl W, Widhalm K, Kostner G, Pollak A 1983 Serum apolipoproteins and lipoprotein(a) during the first week of life. Acta Paediatr Scand 72:505-509

18. Tamir I, Heiss G, Glueck CJ, Christensen B, Kwiterovich P, Rifkind BM 1981 Lipid and lipoprotein distributioons in white children ages 6-19 yr. The Lipid Research Clinics Program Prevalence Study. J Chronic Dis 34:27-39

19. Alaupovic P 1983 Serum apolipoprotein profiles of dyslipoproteinemia. In: Perkins EG, Visek WJ (eds) Dietary Fats and Health. American Oil Chemists' Society, Champaign, IL, pp 574-597

20. Fielding CJ, Shore VG, Fielding PE 1972 Purification and substrate specificity of a protein cofactor of lecithin:cholesterol acyltransferase. Bioochem Biophys Res Commun 46:1493-1498

21. Goldstein JL, Brown MS 1984 Progress in understanding the LDL receptor and $\mathrm{HMG}-\mathrm{CoA}$ reductase, two membrane proteins that regulate the plasma 
cholesterol. J Lipid Res 25:1450-1461

22. Glomset JA 1968 The plasma lecithin cholesterol acyltransferase reaction. J Lipid Res 9:155-167

23. Koren E, McConathy WJ, Alaupovic P 1982 Isolation and characterization of simple and complex lipoproteins containing apolipoprotein $F$ from human plasma. Biochemistry 21:5347-5351

24. Sweeney MJ. Etteldorf JN, Troop LJ. Timma DL, Wrenn EL 1963 Diet and fatty acid distribution in subcutaneous fat and in the cholesterol-triglyceride fraction of serum of young infants. J Clin Invest 42:1-9

25. Dayton S. Hashimoto S, Pearce ML 1966 Composition of lipids in human serum and adipose tissue during prolonged feeding of a diet high in unsaturated fat. J Lipid Res 7:103-111

26. Singer SJ 1974 The molecular organization of membranes. Ann Rev Biochem 43:805-833

27. Cannon PJ 1984 Eicosanoids and the blood vessel wall. Circulation 70:523528

\section{Announcements}

\section{New Horizons in Children's Heart Disease}

On May 28-30 “New Horizons in Children's Heart Disease, An International Symposium” will be held in Toronto, Canada. It is sponsored by the The Hospital for Sick Children and the University of Toronto.

Inquiries: Ms. Ellen Hornung, Department of Cardiology, The Hospital for Sick Children, 555 University Avenue, Toronto, Canada M5G 1 X8, (416) 598-5918.

\section{Society for Behavioral Pediatrics}

The Society for Behavioral Pediatrics will hold its 4th Annual Scientific Meeting on May 9-10, 1986 in Washington, DC in conjunction with the APA-APS-SPR meetings at the Sheraton Washington Hotel. For further information and registration forms, please contact Ms. Noreen Spota at (215) 248-9168 or Dr. Candace Erickson at (212) 305-9862.

\section{Neonatal Screening in 1986 \\ Evian April 28-30, 1986}

European meeting organized by the French Association For The Screening of Metabolic Diseases. The chairman will be Professeur Jean Frézal. The topics include hyperphenylalaninaemias: definition and classification, diagnostic strategy, antenatal diagnosis, maternal PKU. Congenital hypothyroidism: etiological aspects, confirmatory procedures, follow-up results. Other screening programs. The language will be French-English.

For further information: Secretariat du Pr. J. Frézal, Clinique Robert Debré, Hôpital des Enfants Malades, 149, rue de Sèvres, 75743 PARIS Cedex 15, France.

\section{Lung Club}

The annual meeting of the Lung Club will be held at the SPR/APS meetings on Wednesday, May 7th, at 6:30 PM in the South Cotillion Room of the Washington-Sheraton Hotel. This year's speakers are Dr. Solbert Permutt on "Mechanical Interactions Between the Respiratory and Circulatory Systems" and Dr. Alan Jobe on "Ventilation, Lung Development and Lung Damage." Attendance at the Lung Club is open to all without fee. For further information contact Dr. Robert B. Mellins at 212-305-6551. 